\title{
INTERCULTURALIDADE NA UFRGS: A CONTRIBUIÇÃO DE AUGUSTO ÓPE DA SILVA
}

SERGIO BAPTISTA DA SILVA ${ }^{1}$

UFRGS

O falecimento de Augusto Ópẽ da Silva em 31 de maio de 2014 pôs fim a uma longa e densa interlocução que ele soube construir e intensificar nas últimas décadas com extensos setores da sociedade não indígena.

Nossos sentimentos de perda, pesar e tristeza com sua morte trazem de imediato aos nossos espíritos, mentes e corações esta sensação forte e irreparável de descontinuidade abrupta, de finalização irredutível.

No entanto, ao reler minha frase inicial, repensar os ditos contidos em todas as vozes ouvidas após seu falecimento e refletir sobre o escrito nos textos que seguem a esta apresentação-homenagem, doume conta que a riqueza e a intensidade desta relação, as trocas de experiências, emoções e afetos, e os conteúdos interculturais e intercientíficos desta interlocução absolutamente não se extinguem com sua morte.

Augusto soube estabelecer e constituir relações intensas com o mundo não indígena. As alteridades do cosmos dos fóg foram paciente e tenazmente amansadas e pacificadas por este sábio guerreiro kaingang, sempre pronto a conversar, a ouvir, mas, com precisão e diplomacia, sempre sagazmente disposto a nos brindar com seus comentários aguçados e sinceros, que atingiam, por exemplo, os pontos

\footnotetext{
1 Coordenador do Núcleo de Antropologia das Sociedades Indígenas e Tradicionais (NIT/PPGAS/UFRGS); vice-coordenador da RIMP Abya Yala: epistemologias ameríndias em rede (ILEA/UFRGS); integrante da Ação Saberes Indígenas na Escola - Núcleo UFRGS; editor da Espaço Ameríndio. E-mail: sergiobaptistadasilva@gmail.com .
}

Espaço Ameríndio, Porto Alegre, v. 8, n. 2, p. 298-302, jul./dez. 2014. 
débeis ou não pensados pelas políticas governamentais ou por nós mesmos.

Esta sua capacidade crítica, argumentativa e construtiva certamente estava alicerçada em um amplo e profundo conhecimento da epistemologia kaingang. E também em seu pleno e abrangente modo de viver e experenciar a socialidade de seu coletivo.

Augusto, como liderança e conselheiro, soube articular, internamente ao seu grupo, importantes bandeiras vinculadas a conquistas básicas e imprescindíveis aos Kaingang, vizibilizando-as externamente, com destaque para as questões ligadas à terra, à atenção à saúde e à educação específica kaingang. Esta era sua luta diária e constante, que movia inteiramente sua vida. Muitas vezes, ouvi-o dizer: "Não posso ficar parado, me esquentando na beira do fogo".

A marca deste intelectual indígena incansável, que conheci no final da década de 1980, quando ainda trabalhava no Museu Antropológico do Rio Grande do Sul, foi sua constante disponibilidade para falar aos fóg sobre o ponto de vista kaingang nos reduzidos espaços públicos aos poucos conquistados pelo protagonismo indígena, cujo papel exercido por Augusto foi notório. Os artigos e depoimentos que seguem bem o demonstram.

Por isto, quero nesta minha homenagem focar nas relações que Augusto, nos últimos anos, vinha fortalecendo com a Universidade Federal do Rio Grande do Sul (UFRGS), especialmente com os campos da Antropologia e da Educação, enfatizando quatro episódios pontuais, que obviamente não dão conta da série de trocas que Augusto protagonizou com a UFRGS.

O primeiro deles aconteceu em julho de 2007, durante a VII Reunião de Antropologia do Mercosul (VII RAM), ocorrida em Porto Alegre, no Campus Centro da UFRGS, sob a presidência da antropóloga Cornélia Eckert.

Na ocasião, fiz parte de sua comissão científica e desempenhava a chefia do Departamento de Antropologia. Um grupo constituído por muitas pessoas, entre as quais inúmeras lideranças indígenas, professores e alunos, organizamos, à época, no âmbito da VII RAM, um Fórum Indígena Permanente, duas mesas e um espaço, que denominamos Espaço Ameríndio, onde funcionaram durante todo o 
evento oficinas artísticas e de culinária. Augusto participou ativamente da concepção, organização e execução deste projeto e destes eventos indígenas memoráveis que efetivamente ocuparam o Campus Centro da UFRGS. Além disso, Augusto foi painelista da Mesa 2, intitulada "Lutas Ameríndias no Mercosul: orientações originárias ao trabalho antropológico".

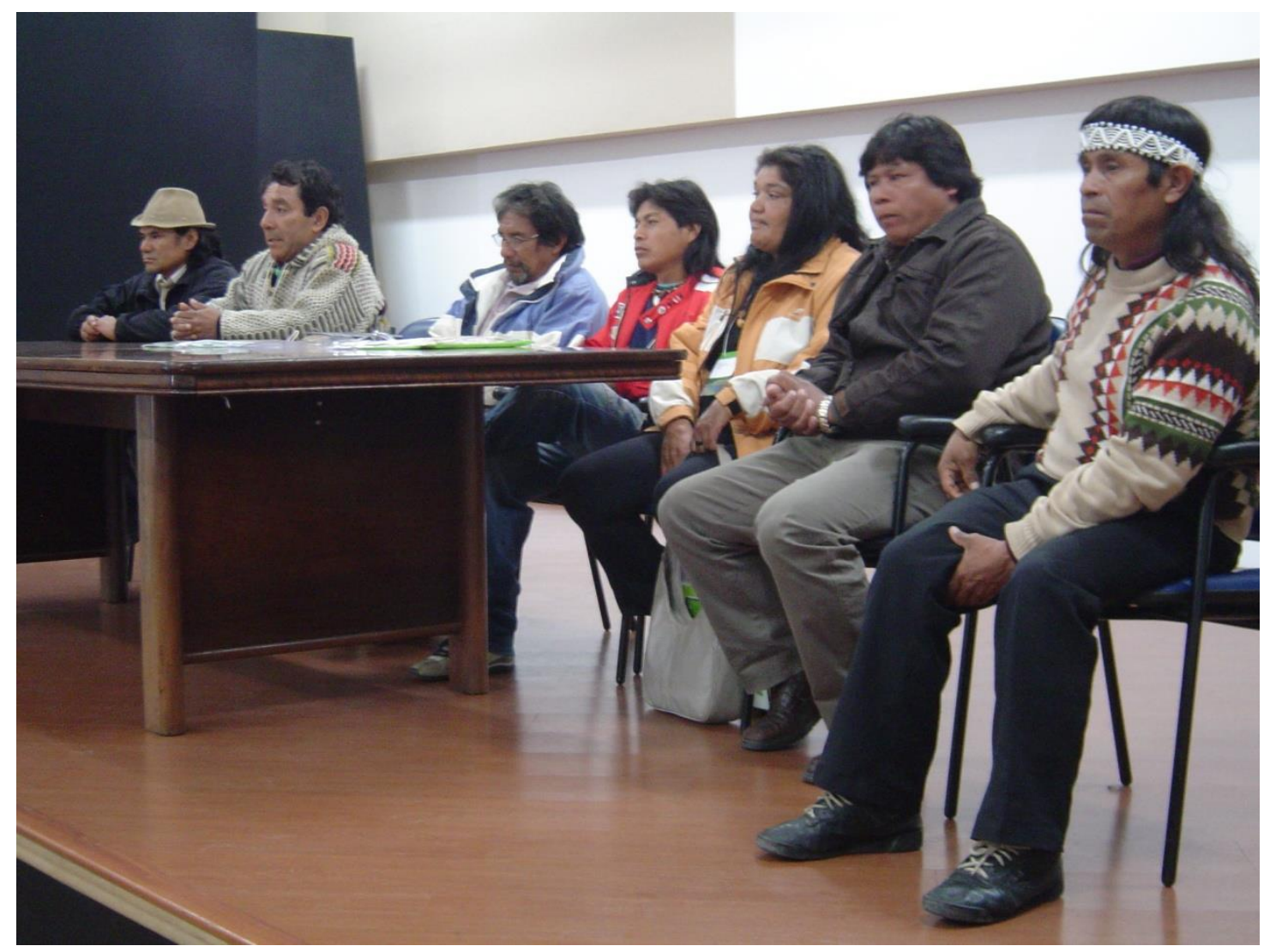

VII RAM, Espaço Ameríndio, sala 101 da FACED, Mesa 2, "Lutas Ameríndias no Mercosul: orientações originárias ao trabalho antropológico", 24/07/2007. Da esquerda para direita: Francisco Roky dos Santos, João Carlos Padilha, Augusto Ópẽ da Silva, José Cirilo Pires Morinico, Maria Silva (in memoriam), Maurício Gonçalves e Dário Tupã Moreira. Acervo do NIT/UFRGS.

O segundo episódio aconteceu aproximadamente na mesma época, um pouco depois. Está inconfundivelmente ligado ao primeiro, e refere-se aos momentos decisivos que se antecederam na UFRGS à implantação do processo seletivo específico para o ingresso de estudantes indígenas, vigente desde 2008. O papel desempenhado por Augusto foi exemplar. 
O terceiro deles é bem mais recente, data do final do ano de 2013, mais precisamente dos meses de setembro e outubro, quando sob a coordenação de Maria Aparecida Bergamaschi, da Faculdade de Educação da UFRGS, delineava-se a Ação Saberes Indígenas na Escola Núcleo UFRGS, da qual Augusto, já doente, participou como pesquisador indígena de toda a elaboração do programa. Suas grandes preocupações sempre foram as de garantir a especificidade dos processos próprios de aprendizagem kaingang, o respeito à concepção kaingang de conhecimento e a manutenção da continuidade das ações desta política governamental.

E, finalmente, o último episódio que queria relatar.

No final de 2013 e inícios de 2014, um grupo de pesquisadores da UFRGS e de outras universidades dentro e fora do Brasil, atendendo a edital do Instituto Latino-americano de Estudos Avançados (ILEAUFRGS), começou a esboçar e planejar um projeto de constituição de rede inter e multidisciplinar de pesquisa, denominado de "Abya Yala: epistemologias ameríndias em rede". Muito recentemente implantado, o projeto está no início de suas atividades.

Seu principal objetivo é o de refletir sobre as relações entre modos de aprendizagem e processos educativos ameríndios e suas correspondentes sócio-mito-cosmo-ontologias, buscando constituir um espaço institucional de articulação de pesquisadores de variadas especialidades e, antes de tudo, incrementar o chamamento para este espaço de interlocução de mais especialistas indígenas (professores, pesquisadores, lideranças, sábios, anciões, xamãs, produtores de vídeos, cineastas, fotógrafos, músicos, entre outros), para que a Rede se torne cada vez mais um espaço dialógico, de interação, de interlocução e de trocas intercientíficas e interculturais intensivas.

O convite para Augusto participar da Rede Abya Yala foi unânime entre nós, integrantes do grupo, tal sua importância no cenário intelectual indígena. 
Ainda estamos, entristecidos, lastimando sua ausência deste e de muitos outros espaços que tão eficientemente Augusto soube construir e ocupar ao longo de sua vida.

$$
<<<0>>>
$$

Nas semanas que se seguiram à morte de Augusto, surgiu com força a ideia de homenagear, de alguma forma, sua memória e suas conquistas. Em diferentes ocasiões, os autores dos artigos que dão sequência a estas homenagens foram amadurecendo esta intenção e construindo conjuntamente como ela se expressaria. Além da série de artigos que ora vêm à lume na Espaço Ameríndio, pensamos também em uma mostra fotográfica, o que traria ao público um outro aspecto de sua liderança: a força de sua imagem, de sua corporalidade, de seus gestos. Este é o plano que projetamos para o futuro.

No início do segundo semestre de 2014, Marília Lourenço, que com Augusto conviveu bastante nos últimos tempos, pois seu campo atual está sendo realizado em Iraí, aceitou o convite para articular a rede de autores presentes nesta homenagem inicial que a ele prestamos: eu próprio, Ana Freitas, Sandro Topẽ da Silva, Rogério Rosa, Valdemar Vicente, a própria Marília, Ilinir Jacinto, Roberto Liebgott, Mauro Casemiro, Matias Rempel, Alessandro Lopes e Roberta Cadaval.

Ao grande líder kaingang Augusto Ópẽ da Silva, à sua memória, às suas conquistas e a seu protagonismo cosmopolítico, deixamos nossas homenagens e nossa certeza da continuidade de seus atos, palavras e ideias. 